\title{
Real Oil Prices, Real Economic Activity, Real Interest Rates, and the US Dollar: A Cointegration Analysis with Structural Breaks
}

\author{
Go Tamakoshi ${ }^{\mathrm{a}}$ and Shigeyuki Hamori, ${ }^{\mathrm{b}}$ \\ ${ }^{a}$ Graduate School of Economics, Kobe University, 2-1, Rokkodai, Nada-ku, Kobe 657-8501, Japan \\ ${ }^{b}$ Faculty of Economics, Kobe University, 2-1, Rokkodai, Nada-ku, Kobe 657-8501, Japan
}

\begin{abstract}
In this paper, we examine the relationship among real oil prices, global economic activity, real value of the US dollar, and real interest rates during the period 1988:1 to 2011:12. We employ the Gregory and Hansen (1996) cointegration test with structural breaks to investigate the long-run equilibrium and analyze the short-term Granger causality as well. Our findings indicate that real oil prices are cointegrated with the three factors mentioned above and are affected positively by real economic activity and negatively by real interest rates and the real value of the US dollar. We also find significant short-run causality from real economic activity to real oil prices, but no significant causality from real interest rate and real value of US dollar to real oil price is detected. These findings are relevant for both policymakers and investors who wish to conduct forecasts for future oil prices on the basis of a solid understanding of its key drivers.
\end{abstract}

Keywords: Oil price, cointegration test with structural breaks, Granger causality, Kilian economic index, interest rate.

\section{INTRODUCTION}

The recent surge in crude oil prices has attracted attention to the key determinants for these prices. An interesting feature is that this surge was accompanied by not only relatively high world economic growth and a noticeable decline in the US dollar, but also generally low level of interest rates over the years. In a demand and supply model for oil, it is widely known that global economic activity and real exchange rate of the US dollar are included in the demand function and hence are regarded as key drivers for oil prices. Moreover, an inverse relationship between oil prices and real interest rates is also justified by economic theory, as argued by Working (1949), in that a lower real interest rate leads to increased hoarding of oil, thereby leading to an increase in its price. Therefore, it is intriguing to conduct an empirical assessment of whether these factors actually influence oil prices through long-run equilibrium and short-term impacts.

Numerous studies have investigated the relationship between real oil prices and global economic activity, regarding the latter as a key determinant of oil prices (e.g., Gately and Huntington, 2002; Griffin and Schulman, 2005; Krichene, 2006, Askari and Krichene, 2008; He et al., 2010). Whilst global economic activity is often represented by world GDP, a recent study by $\mathrm{He}$ et al. (2010) is unique in

*Address corresponding to this author at the Faculty of Economics, Kobe University, 2-1, Rokkodai, Nada-ku, Kobe 657-8501, Japan;

Tel: +81-78-803-6832; E-mail: hamori@econ.kobe-u.ac.jp that they use the Kilian economic index, which is calculated on the basis of representative single voyage freight rates, as an indicator for global economic activity. Using conventional cointegration tests, they reveal that real oil prices are cointegrated with both the Kilian economic index and real exchange rate of the US dollar and that the Kilian index Granger-causes changes in real oil prices.

In contrast, only a few studies have explored the relation between real interest rates and real oil prices. Frankel (2006) identified a negative relationship between the two over the period 1950-1979, employing ordinary least squares regression models. Using a five-variable structural VAR model, Akram (2009) found that commodity prices, particularly oil prices, increased significantly with negative shocks to real interest rates and the US dollar over the period 1990-2007.

This paper extends the study on the relationship between oil prices and its macroeconomic driving forces in keeping with $\mathrm{He}$ et al. (2010), but makes three primary contributions to the body of knowledge on this topic. First, our framework included three key factors (not only global economic activity but also real value of the US dollar and real interest rates) concurrently in estimating the cointegrating relationship with real oil prices. Second, our sample period encompassed the recent surge and fall in oil prices after the fall of the Lehman Brothers. Third and importantly, we employed the Gregory and Hansen (1996) cointegration test, which may yield an accurate model formulation in the presence of a structural break. With an error-correction 
rop

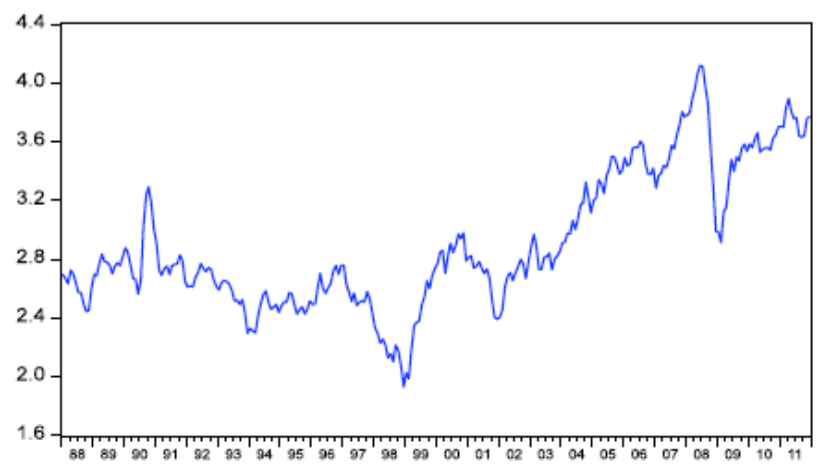

(a) Real price of crude oil (in natural logarithm)

rir

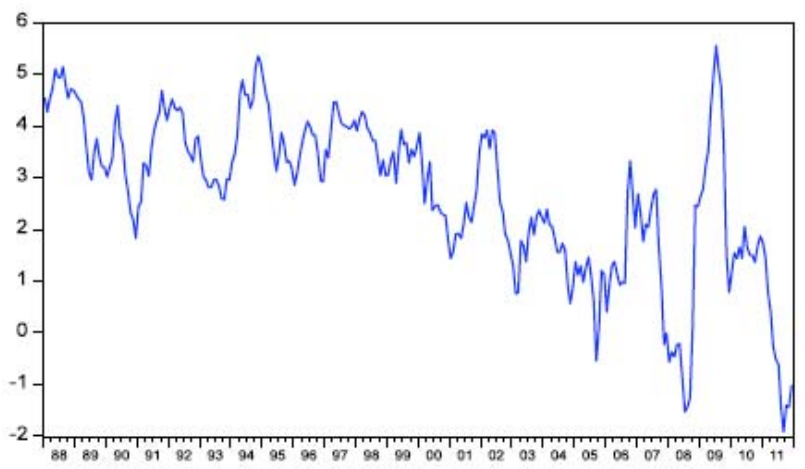

(c) US real interest rate

Figure 1: Historical plots of each time series.

model (ECM) using residuals from the most plausible cointegrating equation, we also analyzed short-run Granger causality among the variables.

\section{DATA}

The data is monthly and spans the period between 1988:1 and 2011:12, including 288 observations. The four variables analyzed in this paper include rop $_{t}$ (real price of crude oil), rea $a_{t}$ (global real economic activity), rex $_{t}$ (real value of the US dollar), and rir $_{t}$ (real interest rate). Following He et al. (2010), we used the WTI crude oil futures price with one-month maturity-

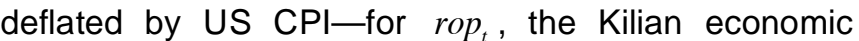
index ${ }^{1}$ for rea $_{t}$, and the trade weighted US dollar index-deflated by US CPI-for rex . With regard to

\footnotetext{
${ }^{1}$ As He et al. (2010) point out, one benefit of employing the Kilian economic index rather than world GDP data is its availability at monthly frequency. Moreover, we can avoid the difficulty of weighting each country's GDP appropriately in order to derive the plausible aggregated data on world GDP.
}

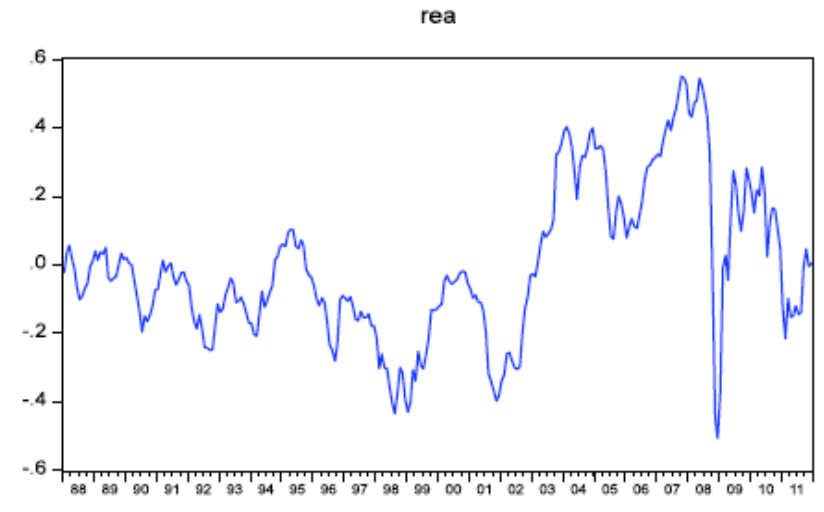

(b) Kilian economic index (in natural logarithm)

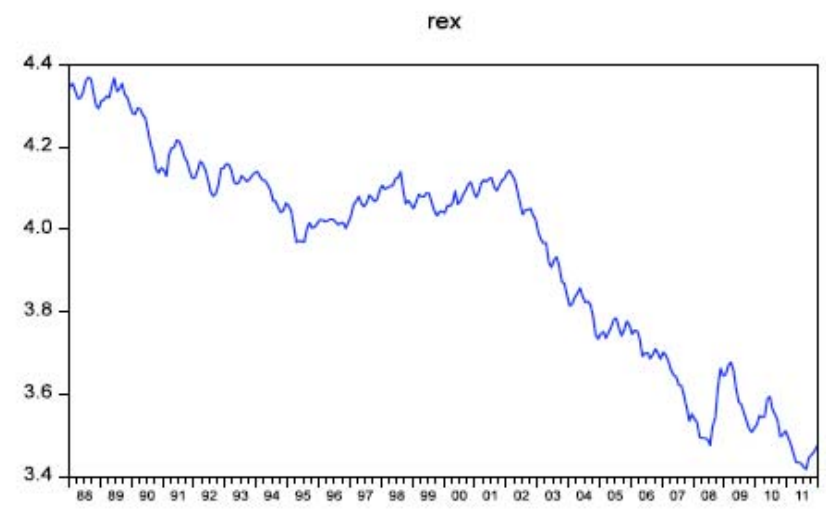

(d) Real exchange value of US dollars (in natural logarithm)

$\mathrm{rir}_{t}$, we used the US real interest, for which the nominal interest rate is measured by the long-term government bond yield because the long-term interest rate may be the most relevant for investment decisions in the real economy. All the variables except real interest rates are expressed in natural logarithm. See the Appendix for details on data sources.

Figure 1 plots each of the four variables for the period 1988:1 to 2011:12. Since the late 1990s, real oil prices have exhibited an increasing trend with the highest peak in July 2008. Despite the marked decline immediately after the collapse of Lehman Brothers in September 2008, the real oil prices recently rose sharply again in early 2009. It is evident that the Kilian global economic index seems to have undergone similar patterns, although the index underwent larger fluctuations. In contrast, the real interest rates and the real value of the US dollar showed decreasing trends during the recent surge in the real prices of crude oil. We implemented the Augmented Dickey-Fuller (ADF) 
test with a constant and a trend term in order to test the null hypothesis of a unit root for each variable. As indicated in Table 1, we found that all the series are I(1) variables at the $5 \%$ level.

\section{Table 1: Results of the ADF Unit Root Tests}

\begin{tabular}{|c|c|c|}
\hline Variables & $\boldsymbol{t}$-statistic & $\boldsymbol{p}$-value \\
\hline \hline rop & -2.9381 & 0.1521 \\
\hline$\Delta$ rop & $-12.5887^{*}$ & 0.0000 \\
\hline rea & -3.2263 & 0.0814 \\
\hline$\Delta$ rea & $-5.4450^{*}$ & 0.0000 \\
\hline rir & -1.6087 & 0.4767 \\
\hline$\Delta$ rir & $-8.6271^{*}$ & 0.0000 \\
\hline rex & -2.1383 & 0.5217 \\
\hline$\Delta$ rex & $-7.4364^{*}$ & 0.0000 \\
\hline
\end{tabular}

*: Statistically significant at the $5 \%$ level.

\section{EMPIRICAL RESULTS}

\section{Cointegration Analysis}

Using the Johansen (1988) cointegration test, we first tested whether the four variables are cointegrated, that is, whether there is a long-run equilibrium among them. Table 2 reports the results of the test. Both trace and maximum eigenvalue statistics suggest that we cannot reject the null hypothesis of no cointegration. This is in sharp contrast to the results of $\mathrm{He}$ et al. (2010), who find the evidence for a cointegration rank of one among the real price of oil, the Kilian economic index, and the real value of the US dollar over the period 1988:1-2007:12, using the Johansen procedure similarly.

However, it is known that the power of such conventional cointegration tests reduces substantially when a structural break exists in the time series. It is reasonable to assume the existence of the structural break in our four variables because they exhibit remarkably large fluctuations in size and breadth over the sample period, as indicated in Figure 1. This motivated us to use the Gregory and Hansen (1996) cointegration test that incorporates the possibility of the structural break, which perhaps offers a higher chance of rejecting the null hypothesis.

The Gregory-Hansen approach permits the accommodation of a single endogenous structural break in a cointegrating relationship, where the change can take several forms. We consider the following three model specifications:

Model 1: Level shift (C)

$y_{t}=\mu_{1}+\mu_{2} d_{t \tau}+\alpha^{T} x_{t}+e_{t}$.

Model 2: Level shift with trend $(C / T)$

$y_{t}=\mu_{1}+\mu_{2} d_{t \tau}+\beta t+\alpha^{T} x_{t}+e_{t}$.

Model 3: Regime shift (C/S)

$y_{t}=\mu_{1}+\mu_{2} d_{t \tau}+\alpha_{1}^{T} x_{t}+\alpha_{2}^{T} x_{t} d_{t \tau}+e_{t}$,

where the dependent variable $y_{t}$ represents rop $_{t}$; the independent variable $x_{t}$ denotes the vector including $r e a_{t}, r e x_{t}$, and $r i r_{t} ; \tau$ is the structural break date; and $d_{t \tau}$ is a dummy variable defined as

$d_{t \tau}=1$ if $t \leq \tau$ and $d_{t \tau}=0$ if $t>\tau$.

In estimating the cointegration equations, we then chose a break date where the ADF test statistic takes the minimum value.

Table 3 shows the results of the Gregory-Hansen tests. In Model 1, cointegration is found between the real price of oil, the Kilian economic index, the real value of the dollar, and the real interest rate at the $5 \%$

Table 2: Johansen Test for Cointegration

\begin{tabular}{|c|c|c|c|}
\hline $\mathbf{H}_{0}$ & $\mathbf{H}_{\mathbf{A}}$ & Trace [ $p$-value] & Max-Eigen [p-value] \\
\hline \hline$r=0$ & $r=1$ & $49.2551[0.4474]$ & $26.5763[0.2043]$ \\
\hline$r=1$ & $r=2$ & $22.6788[0.8897]$ & $11.6057[0.8959]$ \\
\hline$r=2$ & $r=3$ & $11.0731[0.8710]$ & $7.9343[0.8273]$ \\
\hline$r=3$ & $r=4$ & $3.1388[0.8596]$ & $3.1388[0.8596]$ \\
\hline \multicolumn{2}{|r|}{ Conclusion } & $r=0$ & $r=0$ \\
\hline
\end{tabular}

Note: Statistical significance is investigated at the $5 \%$ level. 
Table 3: Gregory-Hansen Tests for Cointegration with Structural Breaks

\begin{tabular}{|c|c|c|c|c|}
\hline Model & GH test statistic & 5\% critical value & 10\% critical value & Break date \\
\hline \hline Model 1: Level shift & $-5.4659^{*}$ & -5.2800 & -5.0200 & $1992 \mathrm{M09}$ \\
\hline Model 2: Level shift with trend & -5.5521 & -5.5700 & -5.3300 & $1993 \mathrm{M} 01$ \\
\hline Model 3: Regime shift & -5.8735 & -6.0000 & -5.7500 & $2004 \mathrm{M} 10$ \\
\hline
\end{tabular}

Note: The critical value are based on Gregory and Hansen (1996). The order of lag lengths is chosen on the basis of the Akaike criterion.

*: Statistically significant at the $5 \%$ level.

level $^{2}$; the identified break date is 1992:9. Hence, our failure to reject the null of no cointegration with the Johansen approach may be because of not incorporating the structural break.

Next, we estimated the cointegration equations for each of the three models using the Engle-Granger method for unknown breaks. The estimation results are displayed in Table 4. We can reasonably conclude that Model 1, for which we found the existence of cointegration, is the most plausible in that all the coefficients are significant at the $5 \%$ level and exhibit expected signs. Specifically, in Model 1, the persistent increase in global economic activity leads to a rise in the real oil prices, while persistent declines in the real interest rates or the real value of the US dollar results in an increase in real oil price. Both the significantly positive coefficient for global economic activity and the significantly negative coefficient for real exchange rate are consistent with the results of He et al. (2010). In addition, the significantly negative coefficient for real interest rates is in keeping with the empirical results of Frankel (2006).

The empirically cointegrating relationship identified above provides support for the validity of the demand and supply structural model for oil prices, which are presented by Krichene (2006) and $\mathrm{He}$ et al. (2010). According to the framework, oil prices are determined by the interrelationship between demand and supply in the long term. While the previous researches suppose that the demand for crude oil is a function of its price, global economic activity, and real exchange rate of the US dollar ${ }^{3}$, our empirical results imply that the demand equation should also include real interests rate. Specifically, the significantly negative coefficient for real interest rate in the cointegrating equation is

${ }^{2}$ In fact, we also find that the null of no cointegration is rejected for Models 2 and 3 at the 10\% significance level. The break dates are 1993:1 and 2004:10, respectively.

${ }^{3}$ On the other hand, oil supply is assumed to be a function of its own price in the abovementioned framework. consistent with the economic theory by Working (1949), which argue that in response to decreases in real interest rate, commodity prices would rise due to reduced production and increased hoarding.

\section{Granger Non-Causality Tests}

Because cointegration exists between the four variables, an error correction term is required when we test Granger causality. We used the residuals from Model 1, the most plausible model, to construct the short-run error correction model (ECM) in the following manner:

$$
\begin{aligned}
& \Delta \operatorname{rop}_{t}=a_{0}+\sum_{i=1}^{k} a_{1 i} \Delta \operatorname{rop}_{t-i}+\sum_{i=0}^{k} a_{2 i} \Delta r e a_{t-i} \\
& +\sum_{i=0}^{k} a_{3 i} \Delta r e x_{t-i}+\sum_{i=0}^{k} a_{4 i} \Delta r i r_{t-i}-\gamma E C M_{t-1}+\varepsilon_{t}
\end{aligned}
$$

where $\gamma$ denotes the speed of adjustment. The Schwarz-Bayesian criterion was used to derive the optimal number of lags $^{4}$. Then, we tested the null hypothesis that lagged differences of each of the three explanatory variables were not significant in explaining changes in the real price of oil. The results of the Granger non-causality tests are presented in Table $\mathbf{5}$. We find evidence of significant causality from real economic activity to real oil price. This is not surprising given that the Kilian economic index is a robust indicator of global demand pressures, reflecting booms and recessions in real economic activity as Kilian (2009) contends, and thus the monthly indicator can be useful for forecasting future oil prices in time. In contrast, Table $\mathbf{5}$ offers little support for the Granger causality from the real interest rate or real exchange rate to real price of oil. The results could be driven by the fact that the theoretically negative relationships between real oil price with real interest rate and real

\footnotetext{
${ }^{4}$ The estimation result of the ECM model is not presented here but is available upon request. We confirmed that the coefficient of the error correction term was significantly negative, which indicates the existence of negative feedback mechanism.
} 
Table 4: Cointegration equations

\begin{tabular}{|c|c|c|c|}
\hline & Model 1 (Dummy: 1992M09) & Model 2 (Dummy: 1993M01) & Model 3 (Dummy: 2004M10) \\
\hline \hline Intercept & $4.6689^{*}[0.0000]$ & $5.9303^{*}[0.0000]$ & $3.8988^{*}[0.0000]$ \\
\hline Intercept x Dummy & $0.3730^{*}[0.0000]$ & $0.3515^{*}[0.0000]$ & $7.4958^{*}[0.0000]$ \\
\hline Trend & & $-0.0008^{*}[0.0322]$ & $0.9179^{*}[0.0000]$ \\
\hline rea & $0.7962^{*}[0.0000]$ & $0.7396^{*}[0.0000]$ & $-0.4443^{*}[0.0025]$ \\
\hline rea x Dummy & & $-0.0988^{*}[0.0000]$ & $-0.1158^{*}[0.0000]$ \\
\hline rir & $-0.0946^{*}[0.0000]$ & & $0.0823^{*}[0.0005]$ \\
\hline rir x Dummy & & $-0.6773^{*}[0.0000]$ & $-0.1854[0.0721]$ \\
\hline rex & $-0.3927^{*}[0.0001]$ & & $-2.0213^{*}[0.0002]$ \\
\hline rex x Dummy & & 0.8329 & 0.8432 \\
\hline Adjusted R-squared & 0.8307 & & \\
\hline
\end{tabular}

Note: $p$-values are in square brackets. "Dummy: 1992M09" indicates that the dummy variable takes unity after September 1992 , for example.

*: Statistically significant at the $5 \%$ level.

Table 5: Granger Non-Causality Tests

\begin{tabular}{|c|c|c|}
\hline Causality investigated & Chi-squared statistics & $p$-value \\
\hline \hline rea $\rightarrow$ rop & $5.3900^{*}$ & 0.0203 \\
\hline rir $\rightarrow$ rop & 2.9771 & 0.0844 \\
\hline rex $\rightarrow$ rop & 0.4028 & 0.5257 \\
\hline
\end{tabular}

Note: The second column contains chi-squared statistics from a Wald test on the lagged differences of the explanatory variables.

*: Statistically significant at the $5 \%$ level.

value of the dollar tend to hold only in the long run rather than in the short run.

\section{CONCLUDING REMARKS}

This article investigated whether there is a longterm relationship between real oil price and global economic activity, real value of the US dollar, and the real interest rate during 1988:1 to 2011:12. The Gregory and Hansen (1996) cointegration test with structural break was employed. After confirming the existence of cointegration, we constructed the ECM model to examine Granger causality from the three driving forces to real price of crude oil.

The following are the key findings of this study: (a) If the structural break is taken into account, there is evidence of long-run cointegrating relationship, where persistent increases in global real economic activity and declines in the real value of the dollar and real interest rate may lead to an increase in real oil price. (b) The significant Granger causality from real economic activity to real crude oil price is identified, whilst there is no short-run causality from real interest rate and real value of US dollar to real oil price. Our findings are particularly helpful for the monetary authority as well as market participants who monitor and forecast future oil prices on the basis of a solid understanding of its key driving factors.

\section{ACKNOWLEDGEMENT}

We are grateful to two anonymous referees for helpful comments and suggestions.

\section{APPENDIX: DATA SOURCES}

- $\quad \operatorname{rop}_{t}$ (real price of crude oil futures with onemonth maturity)-Source: US Energy Information Administration (http://www.eia.gov)

- $\quad r e a_{t}$ (global real economic activity measured by the Kilian economic index)—Source: Lutz Kilian's home page (http://wwwpersonal.umich.edu/ Ikilian)

- $\quad r e x_{t}$ (real value of the dollar measured by the trade weighted US dollar index)-Source: Federal Reserve Bank of St. Louis (http://www.stlouisfed.org)

- $\quad r_{i}$ (US real interest rate measured using the log-term government bond yield and the inflation 
rate)-Source: Datastream and Federal Reserve Bank of St. Louis.

\section{REFERENCES}

Akram, Farooq Q. 2009. "Commodity prices, interest and the dollar." Energy Economics, 31:838-51. http://dx.doi.org/10.1016/j.eneco.2009.05.016

Askari, Hossein. and Krichene, Noureddine. 2008. "Oil price dynamics (2002-2006)." Energy Economics, 30:2134-2153. http://dx.doi.org/10.1016/j.eneco.2007.12.004

Frankel, Jeffery A. 2006. "The effect of monetary policy on real commodity prices." NBER Working Paper 12713.

Gately, Dermot. and Huntington, Hillard G. 2002. "The asymmetric effects of changes in price and income on energy and oil demand." The Energy Journal, 1:19-35.

Gregory, Allan W. and Hansen, Bruce E. 1996. "Residual-based tests for cointegration in models with regime shifts." Journal of Econometrics, 70: 99-126. http://dx.doi.org/10.1016/0304-4076(69)41685-7
Griffin, James. and Schulman, Craig T. 2005. "Price asymmetry in energy demand models: a proxy for energy-saving technical change." The Energy Journal, 26:1-21.

He, Yanan, Wang, Shouyang, and Lai, Kin Keung. 2010. "Global economic activity and crude oil prices: A cointegration analysis." Energy Economics, 32: 868-76. http://dx.doi.org/10.1016/j.eneco.2009.12.005

Johansen, Soren. 1988. "Statistical analysis of cointegration vectors." Journal of Economic Dynamics and Control, 12: 231-54. http://dx.doi.org/10.1016/0165-1889(88)90041-3

Kilian, Lutz. 2009. "Not all oil price shocks are alike: disentangling demand and supply shocks in the crude oil market." American Economic Review, 99: 1053-69. http://dx.doi.org/10.1257/aer.99.3.1053

Krichene, Noureddine. 2006. "World crude oil markets: monetary policy and the recent oil shock." WP/06/62, International Monetary Fund.

Working, Holbrook. 1949. "The theory and price of storage." American Economic Review, 39: 1254-62.

Received on 03-11-2012

Accepted on 18-11-2012

Published on 07-12-2012

DOI: http://dx.doi.org/10.6000/1929-7092.2012.01.4

(C) 2012 Tamakoshi and Hamori; Licensee Lifescience Global.

This is an open access article licensed under the terms of the Creative Commons Attribution Non-Commercial License (http://creativecommons.org/licenses/by-nc/3.0/) which permits unrestricted, non-commercial use, distribution and reproduction in any medium, provided the work is properly cited. 